\section{What is the essence of general practice?}

I think our role is to be informed by guidelines and to help co-create meaning with our patients. ${ }^{1}$ I do not see a fundamental conflict between these actions, and it is not clear to me that one has greater value than the other in maintaining patient safety.

For example, if the patient's condition is ill-defined, as it often is, and the patient's view is different from the doctor's, as it often is, then the application of guidelines may do more harm than good. On the other hand, if the patient and doctor have reached a shared understanding of the situation, then the availability of guidelines can be helpful to both, since it is hard to know all the management options for every condition we encounter

Furthermore, it's not as if there is a single guideline for every condition, and often working out the most applicable elements of multiple guidelines is part of the shared therapeutic journey. Working out how to apply the best available medical evidence in the context of an individual patient (relationship) makes our work intellectually stimulating and (inter-) personally rewarding. That's the job l've been trying to do for the past 20 years and I still can't think of any job I would rather do more.

\section{David J Bossano,}

GP, St Leonard's Practice, Exeter.

Email: davidbossanolanhs.net

\section{Competing interests}

I am a partner at St Leonard's Practice. We are enthusiasts for relationship continuity and my colleagues have published widely on the subject.

\section{REFERENCE}

1. Shah R, Ahluwalia S, Spicer J. A crisis of identity: what is the essence of general practice? $\mathrm{Br} \mathrm{J}$ Gen Pract 2021; DOI: https://doi.org/10.3399/ bjgp21X715745.

\section{Wellbeing is the key}

As Cassell argued, ${ }^{1}$ I think that our role is to help patients restore their wellbeing Both patient safety and the co-creation of meaning for patients' lives are critical in our practices because both are connected to patients' wellbeing. ${ }^{2}$ There are no conflicts between the two. There is only an optimal ratio of the two to achieve each patient's wellbeing.

\section{Koki Kato,}

GP, Madoka Family Clinic, Fukuoka, Japan. Email: koki.katolahcfm.jp

\section{REFERENCES}

1. Cassell EJ. The Nature of Healing: The Modern Practice of Medicine. New York, NY: Oxford University Press, 2012.

2. Shah R, Ahluwalia S, Spicer J. A crisis of identity: what is the essence of general practice? Br J Gen Pract 2021; DOI: https://doi.org/10.3399/ bjgp21X715745.

DOI: https://doi.org/10.3399/bjgp21X716513

\section{The aim of general practice: can it be explained in one sentence?}

As a teacher and researcher, I have learned that, unless my aim is clear, I will confuse myself, my students, my clinical colleagues, and my co-investigators. And yet, as a GP I often wonder, 'Can I summarise my objective?'

The June edition of the UK's British Journal of General Practice included articles describing an existential crisis in primary care lasking 'What is the essence of general practice?'),' a novel study describing some of the most complex work undertaken by GPs (largely invisible to most people most of the time), ${ }^{2}$ and other articles asking how we should deliver care post-COVID.3,4 However, the common thread for me was: 'What is our aim?

And why is it important to be able to explain our aim in a single sentence? When we want the support of our patients, we need to explain how they can help us. And when making the case for funding, we need an elevator pitch - a sentence that quickly conveys our value to the Chancellor of the Exchequer - especially since the aim of other public sectors are obvious: secondary care - scans, operations, infusions; police - public order; military - protection and defence; and education - upskilling.

In my 25 years as a GP, my observation is that we struggle to explain our aim succinctly, and, as a result, I don't think most people know what we do.

Sure, we prevent disease (for example, vaccinations, with SARS-CoV-2 being one of our greatest modern achievements), we screen for disease (for example, smear testing), we treat risk factors (for example, hypertension), we treat isolated disease (for example, infections), we manage complex multiple diseases (multimorbidity), we manage risk (for example, frail older patients), and we are the gatekeepers between illness and disease, ${ }^{5}$ and between the community and secondary care. ${ }^{6}$ How we do this is mysterious. ${ }^{7}$ We the doctor can be the medicine, ${ }^{8}$ we prize continuity of care ${ }^{9}$ and deep doctor-patient relationships, ${ }^{10}$ and we have developed unparalleled communication skills, expertly selecting the consultation style ${ }^{11}$ most appropriate to the patient in front of us.

We have eloquently argued we are essential for the delivery of efficient, ${ }^{6}$ equitable ${ }^{12}$ health services. And we have repeatedly demonstrated our ability to adapt, to increasing demand, ${ }^{13}$ political reorganisation, $^{14}$ bad apples, ${ }^{15}$ and pandemics. ${ }^{16}$

But, in a sentence, what do we do? How do we contribute to national wellbeing?

Perhaps a starting point is to consider the experience of illness. Everyone has been ill, and almost everyone has been a patient. So we all know what it's like when something new happens to our body or mind, or those of a loved one (a symptom). It's unfamiliar. It seeds chaos. It raises practical questions such as: 'Will I be able to ... [insert today's responsibility]?'; 'How long will it last (temporary or permanent)?'; 'Is it going to get worse?'; and 'How long have I got? It causes anxiety, distracting us from our usual activities of living, reducing our ability 
to contribute to the health and wealth of the nation.

And what happens when we seek good-quality primary care? The questions generated by the symptom are answered. We are reassured that we are responding appropriately, doing 'everything possible' (restoring order) including: doing nothing; watching and waiting; having tests; and being seen at the hospital.

So, my attempt to summarise the aim of general practice?

To restore order to the chaos of symptoms so people can contribute to the health and wealth of their nation.

Alastair Hay,

GP, Professor of Primary Care, and NIHR Senior Investigator, Centre for Academic Primary Care, Bristol Medical School: Population Health Sciences, Bristol. Email: Alastair.Haylabristol.ac.uk

\section{Competing interests}

I have no conflicts of interest to declare. I receive funding from the National Institute for Health Research (NIHR) as a Senior Investigator (NIHR 200151) and I have shamelessly espoused the notion of contributing to the health and wealth of the nation from the NIHR.

\section{REFERENCES}

1. Shah R, Ahluwalia S, Spicer J. A crisis of identity: what is the essence of general practice? $\mathrm{Br} \mathrm{J}$ Gen Pract 2021; DOI: https://doi.org/10.3399/ bjgp21X715745.

2. Salisbury C, Lay-Flurrie S, Bankhead CR, et al. Measuring the complexity of general practice consultations: a Delphi and cross-sectional study in English primary care. Br J Gen Pract 2021; DOI: https://doi.org/10.3399/BJGP.2020.0486.

3. Sivarajasingam V. General practice after COVID-19 lessons learned. Br J Gen Pract 2021; DOI: https:// doi.org/10.3399/bjgp21X716009.

4. Misselbrook D. General practice after COVID-19: an introduction to our special series. Br J Gen Pract 2021; DOI: https://doi.org/10.3399/bjgp21X715973.

5. Heath I. Role of fear in overdiagnosis and overtreatment - an essay by lona Heath. BMJ 2014; 349: g6123.

6. Starfield B. Is primary care essential? Lancet 1994 344(8930): 1129-1133.

7. Heath I. The Mystery of General Practice. London: Nuffield Trust, 1995.

8. Balint E. A portrait of Michael Balint: the development of his ideas on the use of the drug 'doctor'. Int J Psychiatry Med 1974; 5(3): 211-222.

9. Mainous AG 3rd, Baker R, Love MM, et al. Continuity of care and trust in one's physician: evidence from primary care in the United States and the United Kingdom. Fam Med 2001; 33(1): 22-27.

10. Ridd MJ, Lewis G. Peters TJ, et al. Patient-doctor depth-of-relationship scale: development and validation. Ann Fam Med 2011; 9(6): 538-545

11. Senior T. The Frankenstein consultation model. Br J Gen Pract 2021; DOI: https://doi.org/10.3399/ bjgp21X715889.

12. Hart JT. The inverse care law. Lancet 1971 1(7696): 405-412

13. Hobbs FDR, Bankhead C, Mukhtar T, et al. Clinical workload in UK primary care: a retrospective analysis of 100 million consultations in England, 2007-14. Lancet 2016; 387(10035): 2323-2330.

14. NHS England. The NHS Long Term Plan. 2019. https://www.longtermplan.nhs.uk/publication/ nhs-long-term-plan laccessed 8 Jul 2021).

15. Baker R. Implications of Harold Shipman for general practice. Postgrad Med J 2004; 80(944): 303-306; discussion 307-308.

16. Greenhalgh T, Choon Huat Koh G, Car J. Covid19: a remote assessment in primary care. $B M J$ 2020; 368: $\mathrm{m} 1182$

DOI: https://doi.org/10.3399/bjgp21X716525

\section{Beyond relational continuity}

I read with interest the proposed mechanisms that link relational continuity to outcomes. The discussion is comprehensive and the proposed theories plausible. It is important to note, though, that most trial evidence supporting continuity and outcomes examines longitudinal, rather than relational, continuity. These two forms of continuity are obviously related and often conflated, but they are different. Despite this, and the lack of trial evidence supporting causation, relational continuity for patients is primary care, and is almost certainly a 'good thing' that should be maximised wherever possible. However, the current constraints of primary care also make relational continuity difficult to deliver for many practices. We also know that not all patients desire relational continuity or, at times, prioritise timely, convenient access over continuity. While policies that attempt to increase relational continuity of care should be advocated for, we need to accept that many patients do not receive relational continuity. It is interesting that the Royal College of General Practitioners has chosen to promote relationship-based care rather than directly advocating for relational continuity.

Patients who may not want, or be able, to see the same clinician want continuity in its other forms. Continuity encompasses more than seeing the same clinician. Models of continuity such as Haggerty's describe several aspects of continuity, including clinicians having access to appropriate information (informational continuity) and patients being treated in a joined-up coherent manner (management continuity). ${ }^{2}$ Patients expect informational and management continuity when being treated in the NHS. Common sense would suggest that a lack of information and a coherent management strategy between clinicians would lead to poor outcomes. However, there is little in-depth research looking at this or how the various forms of continuity, including relational continuity, interact to produce outcomes. While the addition of Sidaway et al's theory to the continuity literature should be welcomed, future research should seek to understand how other forms of continuity influence outcomes. This understanding is needed to optimise outcomes in primary care as it is, rather than how we would like it to be.

Patrick BM Burch,

GP and THIS Institute PhD Fellow, University of Manchester, Manchester.

Email: patrick.burchamanchester.ac.uk

\section{REFERENCES}

1. Sidaway-Lee K, Pereira Gray D, Harding A, Evans P. What mechanisms could link GP relational continuity to patient outcomes? Br J Gen Pract 2021; DOI: https://doi.org/10.3399/bjgp21X716093.

2. Haggerty JL, Reid RJ, Freeman GK, et al. Continuity of care: a multidisciplinary review. BMJ 2003; 327(7425): 1219-1221.

DOI: https://doi.org/10.3399/bjgp21X716537

\section{'You don't know what you've got till it's gone': UK primary care on the global stage}

The last few weeks have been filled with despair at the lack of understanding of everyday pressures in UK general practice by NHS England and the media. Despite being responsible for delivering a worldleading vaccination programme, managing 